\title{
Oxygen can limit heat tolerance in freshwater gastropods: differences between gill and lung breathers
}

\author{
K. Remon Koopman • Frank P. L. Collas • \\ Gerard van der Velde • Wilco C. E. P. Verberk
}

Received: 5 November 2014/Revised: 11 June 2015/Accepted: 20 June 2015/Published online: 16 July 2015

(C) The Author(s) 2015. This article is published with open access at Springerlink.com

\begin{abstract}
Insufficient oxygen delivery to tissues is hypothesised to limit thermal tolerance, but evidence in ectotherms is mixed. We assessed heat tolerance under hypoxia, normoxia and hyperoxia to test whether the extent in which oxygen can lower or increase heat tolerance differed with mode of respiration, comparing gill-breathing caenogastropods and lung-breathing pulmonates with or without an accessory gill. Hypoxia lowered heat tolerance in three of the four pulmonates (Physa fontinalis, Physa acuta and Planorbis carinatus) by $1.2-2.1^{\circ} \mathrm{C}$. Hyperoxia, however, did not increase the heat tolerance in any of
\end{abstract}

Electronic supplementary material The online version of this article (doi:10.1007/s10750-015-2386-y) contains supplementary material, which is available to authorized users.

Handling editor: Marcelo S. Moretti

K. R. Koopman $(\bowtie) \cdot$ F. P. L. Collas

Department of Environmental Science, Institute for Water and Wetland Research, Radboud University Nijmegen,

Heyendaalseweg 135, 6525 AJ Nijmegen, The

Netherlands

e-mail: K.Koopman@science.ru.nl

K. R. Koopman · F. P. L. Collas · G. van der Velde · W. C. E. P. Verberk

Department of Animal Ecology and Ecophysiology, Institute for Water and Wetland Research, Radboud University Nijmegen, Nijmegen, The Netherlands

G. van der Velde

Naturalis Biodiversity Center, Leiden, The Netherlands the pulmonate species. Thus, heat tolerance limits of these pulmonates does not appear to be oxygen limited under normoxia, possibly because of their high capacity to regulate oxygen consumption associated with aerial gas exchange. Instead, other processes may become limiting at thermal extremes such as loss of protein function, loss of membrane stability or neuronal dysfunction. The caenogastropod species tested (Potamopyrgus antipodarum, Bithynia tentaculata) closed their operculum during the warming experiments. This behavioural response prevented us from obtaining clear results. Nevertheless, our results suggested hyperoxia may increase heat tolerance in $B$. tentaculata. This could be related to its lower capacity to regulate oxygen, owing to its fully aquatic gas exchange mechanism.

Keywords Hypoxia $\cdot$ Hyperoxia $\cdot$ Respiration physiology $\cdot$ Molluscs $\cdot$ Thermal tolerance

\section{Introduction}

Temperature is considered to be a primary driver of species distributions (e.g. Root et al., 2003; Calosi et al., 2010; Sunday et al., 2011). The thermal tolerance of a species can be considered as a key trait, which can be used to predict biological responses to a rapidly changing climate (Chown, 2012). The oxygen limitation hypothesis posits that the detrimental effects of warming in ectothermic animal species are 
not directly caused by high temperatures per se, but instead result from oxygen limitation (Winterstein, 1905; Pörtner, 2001, 2010). As temperatures increase there is a progressive mismatch between tissue oxygen demand and the capacity of an animal for oxygen delivery to its tissues. Warming reduces the solubility of oxygen in water, while maximum rates of oxygen diffusion can be slightly enhanced as the diffusion coefficient of oxygen in water increases with temperature (Dejours, 1981; Woods, 1999; Verberk et al., 2011). As oxygen consumption by the animal increases more than oxygen diffusion rates, water can become oxygen depleted, and consequently an aquatic animal may experience a lower availability of oxygen (Verberk \& Atkinson, 2013). As a result, warming makes it increasingly difficult for an animal to either extract sufficient oxygen from the water due to a limited capacity for ventilation or transport sufficient oxygen to its tissues due to a limited cardiovascular capacity, eventually giving rise to critical temperatures (CTs), at which point the animal can no longer supply sufficient oxygen to its tissues (Winterstein, 1905; Bennet, 1978; Pörtner, 2001). Oxygen shortage results in lower cellular energy levels, a situation which can only be temporarily remediated by anaerobic metabolic activity. This lack of energy causes the animal to enter a comatose state where its survival is passive and time-limited (Pörtner, 2002, 2010).

A key prediction following from the hypothesis that thermal limits arise through oxygen limitation at the whole-animal level before lower levels of biological organisation are damaged directly by heat (e.g. protein denaturation or membrane instability) is that higher oxygen levels should raise the heat tolerance of an animal, whereas lower oxygen levels reduce its heat tolerance. Several studies have tested this prediction in a range of species, such as fish (Mark et al., 2002), crustaceans (Ern et al., 2014, 2015), insects (Klok et al., 2004; Stevens et al., 2010; Verberk \& Bilton, 2011, 2013, 2015; Verberk \& Calosi, 2012; Neven et al., 2014), bivalves (Pörtner et al., 2006) and marine gastropods (Davenport \& Davenport, 2007). The extent to which thermal tolerance limits depend on ambient oxygen levels was found to vary among species, e.g. studies that focussed on terrestrial, airbreathing insects report little or no evidence for oxygen limited thermal tolerance (Klok et al., 2004; Stevens et al., 2010; Neven et al., 2014). The prediction that oxygen modulates thermal limits was better supported in aquatic arthropods and fish, but again support was not universal (see e.g. Verberk \& Bilton, 2013; Ern et al., 2014, 2015; Lefevre et al., 2015). To account for these differences among species, Verberk \& Bilton (2013) suggested that the extent to which oxygen limits thermal tolerance, could be related to the capacity of a species to regulate their oxygen uptake (i.e. its regulatory capacity). The capacity to regulate oxygen uptake is intrinsically more challenging in water than in air. Compared to air, water has a higher density and viscosity and oxygen diffusion rates are orders of magnitude lower (Jones, 1972; Dejours, 1981; Verberk et al., 2011). As a result, air-breathing insects can easily regulate their oxygen uptake, while regulating their oxygen uptake is more difficult for underwater gas exchangers (Verberk \& Atkinson, 2013).

When comparing pairs of insects from four different orders, Verberk \& Bilton (2013) found heat tolerance was consistently less impacted by hypoxia in species that were better at regulating oxygen uptake (e.g. surface exchangers) compared to species that had a poor capacity to regulate oxygen uptake (e.g. aquatic gill and tegument breathers). These results were confirmed by experimental manipulations to isolate the effect of capacity to regulate oxygen uptake within a single species (Verberk \& Bilton, 2015). These results provide a concept, in which the capacity to regulate gas exchange dictates the extent to which heat tolerance is limited by oxygen. Although based on insects, the concept may also apply to other animal groups. Here we test this idea using freshwater gastropods. Like insects, gastropods are ectotherms that utilise various modes of respiration: all gastropods breathe through their skin but some species also use gills to retrieve oxygen from the water (e.g. caenogastropods), while others have a lung which they use to breathe air (pulmonates). Since freshwater gastropods retrieve oxygen from either water or air, or both, it is likely that they differ in their capacity to regulate oxygen uptake due to the differences between water and air as a respiratory medium. Several other characteristics likely affect their capacity to regulate oxygen uptake. Some pulmonates possess both a lung and an accessory gill allowing them to retrieve oxygen from air and water, respectively (Gittenberger et al., 2004; Zukowski \& Walker, 2009). For example, the pulmonate family Physidae possess mantle lobes which can cover the shell and are believed to have a 
respiratory function as accessory gills (WesenbergLund, 1939; Jordan, 1951; Hutchinson, 1993). They can also fill their mantle pocket with water and use it as a derived gill (McMahon, 1983). In addition, gastropods make use of different respiratory pigments in their haemolymph, affecting their capacity to regulate oxygen uptake. For example, the high oxygen affinity of haemoglobin in Planorbarius corneus (Linnaeus, 1758) allows it to exploit its pulmonary oxygen to a greater extent than Lymnaea stagnalis (Linnaeus, 1758) which has haemocyanin (Jones, 1961).

In this study, we compare the effect of ambient oxygen levels on heat tolerance of several freshwater gastropod species, with different modes of respiration (lung vs. gill breathers vs. lung breathers with an accessory gill). We test the idea that a species' capacity to regulate its oxygen uptake determines the extent to which heat tolerance limits depend on ambient oxygen levels. We hypothesise that the gill-breathing caenogastropods would be most vulnerable to the interactive effects of warming and hypoxia and have the highest increase in heat tolerance under hyperoxia, owing to their lower capacity to regulate oxygen uptake due to a fully aquatic gas exchange. The heat tolerances of the lung-breathing pulmonate gastropods are expected to be less affected by ambient oxygen levels due to their higher capacity to regulate oxygen uptake arising from aerial gas exchange. Within the pulmonate species, Physidae utilise haemocyanin as a respiratory pigment (e.g. Smith et al., 1996) and have an accessory gill, which likely causes them to rely more on aquatic gas exchange, whereas the Planorbidae have a greater reliance on aerial gas exchange and have haemoglobin as a respiratory pigment (Ghiretti \& Ghirefli-Maguldi, 1972). Because of the likely greater capacity of Planorbidae to regulate oxygen uptake, oxygen levels are expected to affect heat tolerance less in the Planorbidae than in the Physidae.

\section{Materials and methods}

Species collection and acclimation

Adults of six gastropod species, two caenogastropod species [Bithynia tentaculata (Linnaeus, 1758), Potamopyrgus antipodarum (Gray, 1843)] and four pulmonate species [Physa fontinalis (Linnaeus, 1758), Physa acuta Draparnaud, 1805 (syn. Physella acuta),
Planorbis carinatus Müller, 1774, Planorbis planorbis (Linnaeus, 1758)] differing in their modes of respiration were collected in the vicinity of Nijmegen, The Netherlands during the summer of 2013 (June and August; Table 1). Nearly all species were gathered from a ditch with slow flow located near the A73 highway $(51.794139,5.8043167)$, except $P$. antipodarum which was collected from the floodplain lake Bemmelse waard (51.879722, 5.9068333).

Individuals were transported to the laboratory and kept at a temperature of $10^{\circ} \mathrm{C}$ and a $12 \mathrm{~L}: 12 \mathrm{D}$ regime. Before recording CTs, all species were acclimated for at least 7 days to $10^{\circ} \mathrm{C}$ to reduce variability in thermal history (McMahon \& Russell-Hunter, 1981). Individuals were also gradually acclimated to Dutch standard water (DSW; $\mathrm{pH}=7.9 \pm 0.1$ and conductivity $=576 \pm$ $44 \mu \mathrm{S} \mathrm{cm}^{-1}$ ). From the second day onwards, water from their field location was partially replaced by DSW to reach 50\% DSW in the second day, 75\% DSW in the third day and $100 \%$ DSW in the fourth day. During the acclimation period the individuals were supplied with the plant material on which they were collected. The large quantities of this plant material supplied to the specimens of each species provided sufficient food and allowed them to be well maintained in the laboratory.

Assessing thermal tolerance according to critical temperatures $\left(\mathrm{CT}_{\max }\right)$

Assessment of thermal tolerance was based on CTs $\left(\mathrm{CT}_{\max }\right)$ and carried out according to the experimental protocol described in Verberk \& Calosi (2012). A schematic overview of the experimental set-up is presented in Online Resource 1. Individual snails were placed in an air-sealed flow-through chamber $\left(0.04 \mathrm{~s} \mathrm{~s}^{-1}\right)$ to which water was supplied through gravity from a 501 header tank. Water was collected in a collection tank and pumped back into the header tank. The water used in the experiment was DSW (same composition as used for acclimation) and was aerated with different gas mixtures of oxygen and nitrogen produced by a Witt gas-mixer KM 100-3 MEM (1) (Witt-Gasetechnik GmbH \& Co KG, Salinger Feld, Germany). This allowed us to create three oxygen conditions: hypoxia (5 $\mathrm{kPa}$ or $25 \%$ air saturation), normoxia (20 kPa or $100 \%$ air saturation) and hyperoxia (60 kPa or $300 \%$ air saturation). The values chosen for the oxygen conditions were similar to experimental 
Table 1 The species used in the experiments that utilised different modes of respiration

\begin{tabular}{lc}
\hline Species & Mode of respiration \\
\hline Bithynia tentaculata (Linnaeus, 1758) & Gill \\
Potamopyrgus antipodarum (Gray, 1843) & Gill \\
Physa fontinalis (Linnaeus, 1758) & Lung and accessory gill \\
Physa acuta Draparnaud, 1805 & Lung and accessory gill \\
Planorbis planorbis (Linnaeus, 1758) & Lung \\
Planorbis carinatus Müller, 1774 & Lung \\
\hline
\end{tabular}

conditions used in other studies (e.g. Verberk \& Calosi, 2012; Verberk \& Bilton, 2013) to allow for a comparison between our results and the results of these studies. Furthermore, as air breathers are generally less sensitive to lower oxygen values (e.g. Verberk \& Bilton, 2015), a low oxygen concentration was chosen to ensure that an effect of hypoxia could be detected in the air-breathing gastropods. Critical oxygen tensions for freshwater gastropods are reported to be below $2.5 \mathrm{kPa}$ (at $15^{\circ} \mathrm{C}$; Jones, 1961) and thus these oxygen levels did not affect survival at the start temperature of $10^{\circ} \mathrm{C}$. Moreover, such low oxygen values can occur in the gastropod habitat as dissolved oxygen levels are known to fluctuate on a diurnal basis (Jones, 1961).

Each flow-through chamber also included a small head space holding a layer of air. The air in this compartment could also be exchanged via a needle with different gas mixtures of oxygen and nitrogen (see Online Resource 2), in such a way that the air and water compartments held the same gas mixture. Equilibration of the air compartment with the atmosphere was prevented by the capillary action of water sealing off the opening (see Online Resource 2). The air-layer mixture was produced by two mass flow controllers (Mass Stream, M+W Instruments GmbH, Germany) and supplied to the air layer using a needle. To prevent that oxygen in the water equilibrated with the atmosphere, the header and collection tank were sealed off with 18-mm-thick expanded polystyrene sheeting and a layer of plastic material.

Before the warming trial, the individuals were given a 1-h resting period at $10^{\circ} \mathrm{C}$ to minimise effects of handling stress and ensure that all individuals were out of their shells at the start of the experiment. Ten minutes after the start of this resting period, the gas mixture was adjusted to achieve the desired level of oxygenation in the water at the end of this resting period. Oxygen levels of the water outflow were measured every $15 \mathrm{~min}$ during this resting period to ensure that oxygen levels were stable at the start of the heating process. Preliminary trials showed that nominal output values of the gas mixture supplied to the water had to be slightly more extreme (for hypoxia $3 \% \mathrm{O}_{2}$ and $97 \% \mathrm{~N}_{2}$ and for hyperoxia $65 \% \mathrm{O}_{2}$ and $35 \% \mathrm{~N}_{2}$ ) in order to achieve the desired levels of dissolved oxygen of $5 \mathrm{kPa}$ for hypoxia and $60 \mathrm{kPa}$ for hyperoxia. In addition, the air layer in each chamber was aerated for $10 \mathrm{~s}$ at the start of the resting period with a mixture of 5,20 or $60 \mathrm{kPa} \mathrm{O}_{2}$ depending on the treatment. To compensate for any gas exchange between water and air layer during the resting period, the air layer was aerated again at the end of the resting period.

When oxygen levels were stable, after the resting period, the temperature was gradually increased $\left(0.25^{\circ} \mathrm{C} \mathrm{m^{-1 }}\right)$ using a Grant R5 water bath with a GP200 pump unit (Grant Instrument Ltd., Cambridge, UK) which was connected to a tubular counter-current heat exchanger that heated the water before it flowed through the chambers. As the ramping rate is known to affect the CT (e.g. Terblanche et al., 2007; Rezende et al., 2014), we adopted a ramping rate of $0.25^{\circ} \mathrm{C}$ $\min ^{-1}$ in order to be able to compare our results to other studies that used the same ramping rate (e.g. Klok et al., 2004; Verberk \& Calosi, 2012; Verberk \& Bilton, 2013). The temperatures were logged using a HH806AU digital thermometer (Omega Engineering, Inc., Stamford, USA). During the warming trial, the thermal endpoints were measured. At the end of each warming trial, each individual was removed from the flow-through chamber and its biomass (ash-free dry weight) was determined.

\section{Determining $\mathrm{CT}_{\max }$}

To determine the $\mathrm{CT}_{\max }$ of the various species, three endpoints were used: (1) loss of movement, (2) first retraction into the shell (with closed operculum, if 
the species had one) and (3) last retraction into the shell. All endpoints are indicative of high heating stress, with gastropods no longer being able to escape from the environmental conditions that will eventually kill them, which is the endpoint relevant for critical thermal maxima $\left(\mathrm{CT}_{\max }\right.$; Lutterschmidt \& Hutchinson, 1997). Each species generally displayed one of the first two endpoints, with the pulmonates displaying loss of movement and the caenogastropods displaying first retraction into their shell. Only for $B$. tentaculata both the first and last retraction into the shell (third endpoint) were used, since individuals of this species would sometimes open their operculum and emerge again for several times after the first retraction into the shell. So for $B$. tentaculata, $\mathrm{CT}_{\max }$ was the temperature of the first retraction into the shell (with closed operculum), which was the same endpoint as used for $P$. antipodarum, and $\mathrm{CT}_{\text {last-retraction was the temperature }}$ of the last retraction into the shell (with closed operculum). Between the first and last retraction, $B$. tentaculata never fully emerged out of its shell again. Therefore, the temperature of the first retraction could still be considered $\mathrm{CT}_{\max }$, since $B$. tentaculata was no longer able to escape from the surrounding conditions. For each species, heat tolerance was assessed for 10 individuals during each oxygen treatment, making a total of 30 individuals per species. Some individuals of the two pulmonate planorbid species, $P$. planorbis and $P$. carinatus, retracted into their shell, preventing evaluation of the $\mathrm{CT}_{\max }$ value associated with the endpoint loss of movement. Since this problem was limited to 6 individuals (out of the 60 individuals assessed for the two species), we decided to exclude these measurements and for these species only present the $\mathrm{CT}_{\max }$ values at which loss of movement occurred. Furthermore, preliminary analyses that did include these six individuals were not qualitatively different, indicating our results are not biased by this decision.

\section{Number of visits to the surface}

In addition to $\mathrm{CT}_{\max }$, the total number of times the pulmonate gastropods migrated from the bottom to the water surface (and back to the bottom), during the experiment, for taking up air was recorded (number of surface visits). An increasing number of surface visits indicates an increased oxygen demand, as Jones
(1961) showed that animals increasingly relied on aerial gas exchange to meet elevated oxygen demands in warmer water.

\section{Data analysis}

In order to test if oxygen affected the thermal tolerance of species and if there were differences in thermal tolerance between the species utilising various modes of respiration (as a proxy for different capacities to regulate oxygen uptake), an analysis was performed using an ANOVA. The defined dependent variable was $\mathrm{CT}_{\max }$ and the fixed factors were 'oxygen level', 'mode of respiration' and 'species' with 'species' being nested within 'mode of respiration'. Preliminary analysis showed that the covariate 'biomass' did not influence the thermal tolerance $(P=0.677)$ and was therefore left out of the analysis, allowing the use of an ANOVA. Finally, the interaction 'mode of respiration' $x$ 'oxygen level' was defined.

In order to test for an effect of oxygen on the number of surface visits, the same ANOVA-design as used for testing the effects of oxygen on $\mathrm{CT}_{\max }$ was chosen, but with 'number of surface visits' as the dependent variable. Again, preliminary analysis indicated 'biomass' did not affect the number of surface visits $(P=0.960)$ and was therefore excluded from the final model.

The assumption of the homogeneity of variances was not met, even if the data were log or square root transformed. The Kolmogorov-Smirnov test revealed that $\mathrm{CT}_{\max }$ and number of surface visits deviated from a normal distribution $\left(\mathrm{CT}_{\max }\right.$ : $P<0.001$, number of surface visits: $P<0.001$ ). These difficulties for $\mathrm{CT}_{\max }$ were partly the result of a few outlying values found for the pulmonate species. Violation of the assumption of homogeneity becomes more of a problem when sample sizes were unequally distributed. However, the sample sizes were largely equal across all analyses (30 individuals per species) except for the Planorbidae in the $\mathrm{CT}_{\max }$ analyses (29 for $P$. carinatus and 25 for $P$. planorbis). Therefore, it was decided to (i) present the results of the ANOVA analyses as an indication of the simultaneous effects of species, modes of respiration and oxygen, and (ii) also to employ nonparametric post hoc tests. Mann-Whitney $U$ tests were used to test for differences in $\mathrm{CT}_{\max }$ or number of surface visits between the three oxygen treatments. 
As multiple comparisons increase the chance of making a type I error, we applied a Bonferroni correction by testing against an $\alpha$-value of 0.0167 (=0.05/3 comparisons).

\section{Results}

Critical thermal maxima

Heat tolerances differed between species $(F=42.626$; $P<0.001)$ and between modes of respiration $(F=$ 23.850; $P=0.014$; Table 2$)$. Overall, oxygen significantly affected the critical thermal maxima $(F=$ 8.192; $P<0.001)$ with lower values for $\mathrm{CT}_{\max }$ being recorded under hypoxic conditions. This effect of oxygen differed between species having a different mode of respiration (a significant interaction between mode of respiration and oxygen level; $F=3.154$; $P=0.016$ ). Pulmonate gastropods generally showed loss of movement at lower temperatures under hypoxia $\left(\Delta 1.2-2.1^{\circ} \mathrm{C}\right)$, while caenogastropods retracted into their shell more or less indifferent of oxygen conditions (Fig. 1).

In B. tentaculata, there was a trend for improved heat tolerance under hyperoxia when measured as $\mathrm{CT}_{\text {last-retraction. Relative to normoxia, heat tolerance }}$ increased under hyperoxia by $4.7^{\circ} \mathrm{C}$ (Fig. 1; MannWhitney $U$ test: $P=0.07$ ).

Number of visits to the surface

Similar to $\mathrm{CT}_{\max }$, oxygen also affected the number of surface visits of pulmonate gastropods $(F=71.435$; $P<0.001)$. The pulmonate gastropods surfaced more often to breathe air under hypoxia (two-seven times more; Fig. 2). No differences in number of surface visits among pulmonate species $(F=2.788 ; P=$ 0.066), and between modes of respiration $(F=4.961$; $P=0.156$ ) were found (Table 3). However, the response to oxygen did differ between the mode of respiration (interaction of mode of respiration * oxygen level: $F=19.892 ; P<0.001$ ), with the Physidae increasing the number of surface visits more steeply in response to hypoxia than the Planorbidae.

\section{Discussion}

Our results indicate a small, but significant effect of hypoxic conditions on upper thermal limits in three freshwater pulmonate gastropod species. The heat tolerance of $P$. fontinalis, $P$. acuta and $P$. carinatus was lowered by $1.2-2.1^{\circ} \mathrm{C}$ under hypoxia (Fig. 1). Studies on several aquatic insects using the same methodology and oxygen conditions report a decreased thermal tolerance under hypoxia ranging from 1.2 to $13.3^{\circ} \mathrm{C}$ (average of $5.1^{\circ} \mathrm{C}$ ) (Verberk \& Calosi, 2012; Verberk \& Bilton, 2013; Verberk et al., 2013). So, the decrease of $1.2-2.1^{\circ} \mathrm{C}$ reported here is relatively modest. Additionally, the frequency of surfacing of the three pulmonate gastropods species increased sharply not only under hypoxia (Fig. 2), but also under normoxia when temperatures where high $\left(>20^{\circ} \mathrm{C}\right)$, suggesting that oxygen may become limiting under these conditions. Similar increases in aerial respiration under hypoxia have been observed in $L$. stagnalis (Linnaeus, 1758) and P. corneus (Linnaeus, 1758) (Jones, 1961; Lukowiak et al., 1996). Under hypoxia, the two Physidae species increased their number of surface visits more sharply than the two Planorbidae species. This corroborates the hypothesised

Table 2 The results of the overall analysis of $\mathrm{CT}_{\max }$ (measured as loss of movement in the pulmonates and the first retraction into the shell in the operculate caenogastropods) in relation to species, mode of respiration and oxygen level

\begin{tabular}{|c|c|c|c|c|}
\hline Sources & SS (type III) & d.f. & $F$-ratio & $P$ value \\
\hline Species (mode of respiration) & 317.796 & 3 & 42.626 & $<0.001$ \\
\hline Mode of respiration & 5056.35 & 2 & 23.85 & 0.014 \\
\hline Oxygen level & 40.725 & 2 & 8.192 & $<0.001$ \\
\hline Mode of respiration $*$ oxygen level & 31.36 & 4 & 3.154 & 0.016 \\
\hline
\end{tabular}

Significant results are indicated in bold

SS (type III) the sum of squares type III, d.f. degrees of freedom 

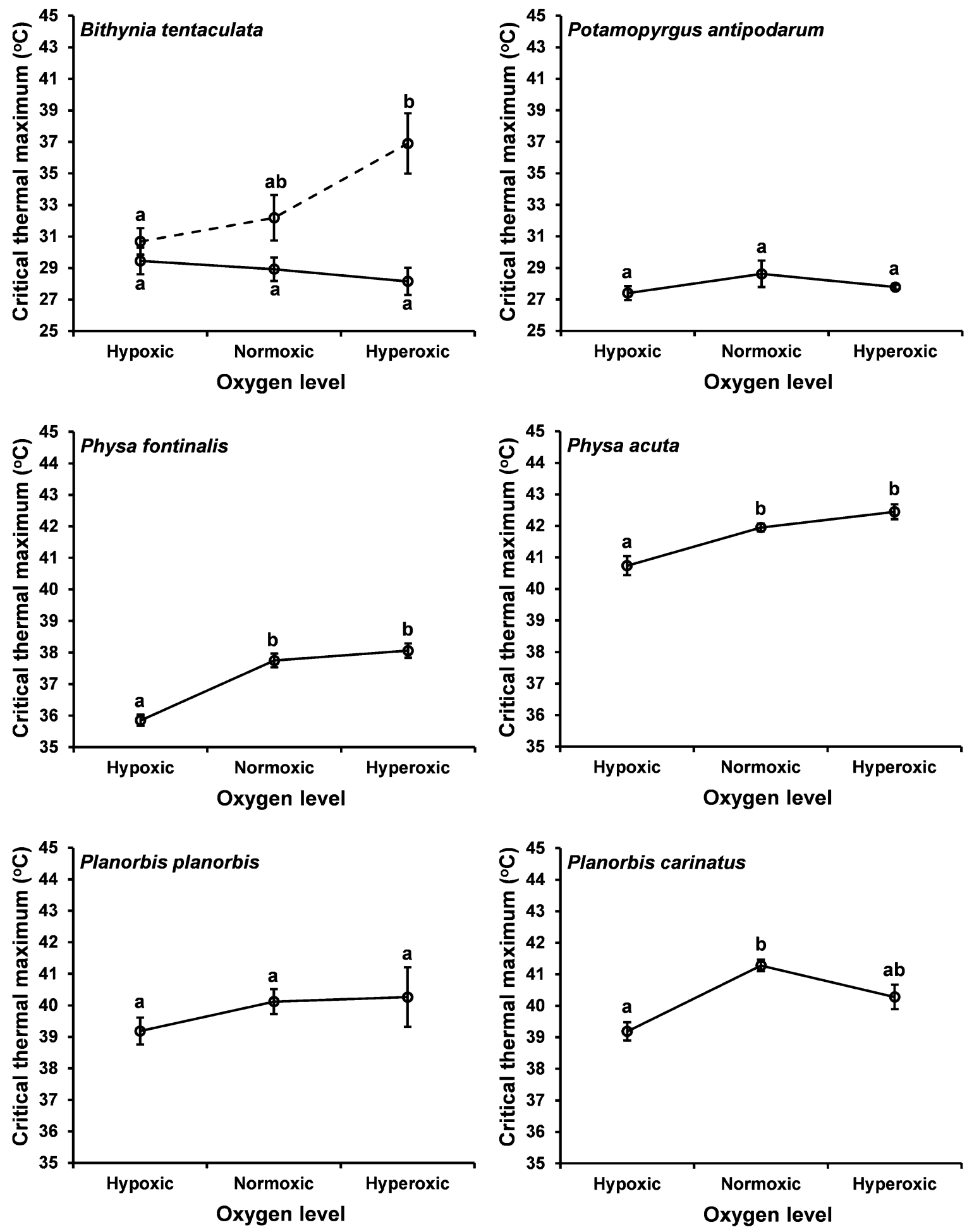

Fig. 1 The critical thermal tolerance maxima $\left(\mathrm{CT}_{\max }\right)$ based on loss of movement under hypoxia, normoxia and hyperoxia for the six gastropod species. Values for Bithynia tentaculata are $\mathrm{CT}_{\max }$ (open circles with solid line) and $\mathrm{CT}_{\text {last-retraction (open circles }}$

with dashed line) based on retraction into the shell and closing of the operculum. Letters indicate significant differences according to non-parametric testing (Mann-Whitney $U$ ), error bars represent standard error 

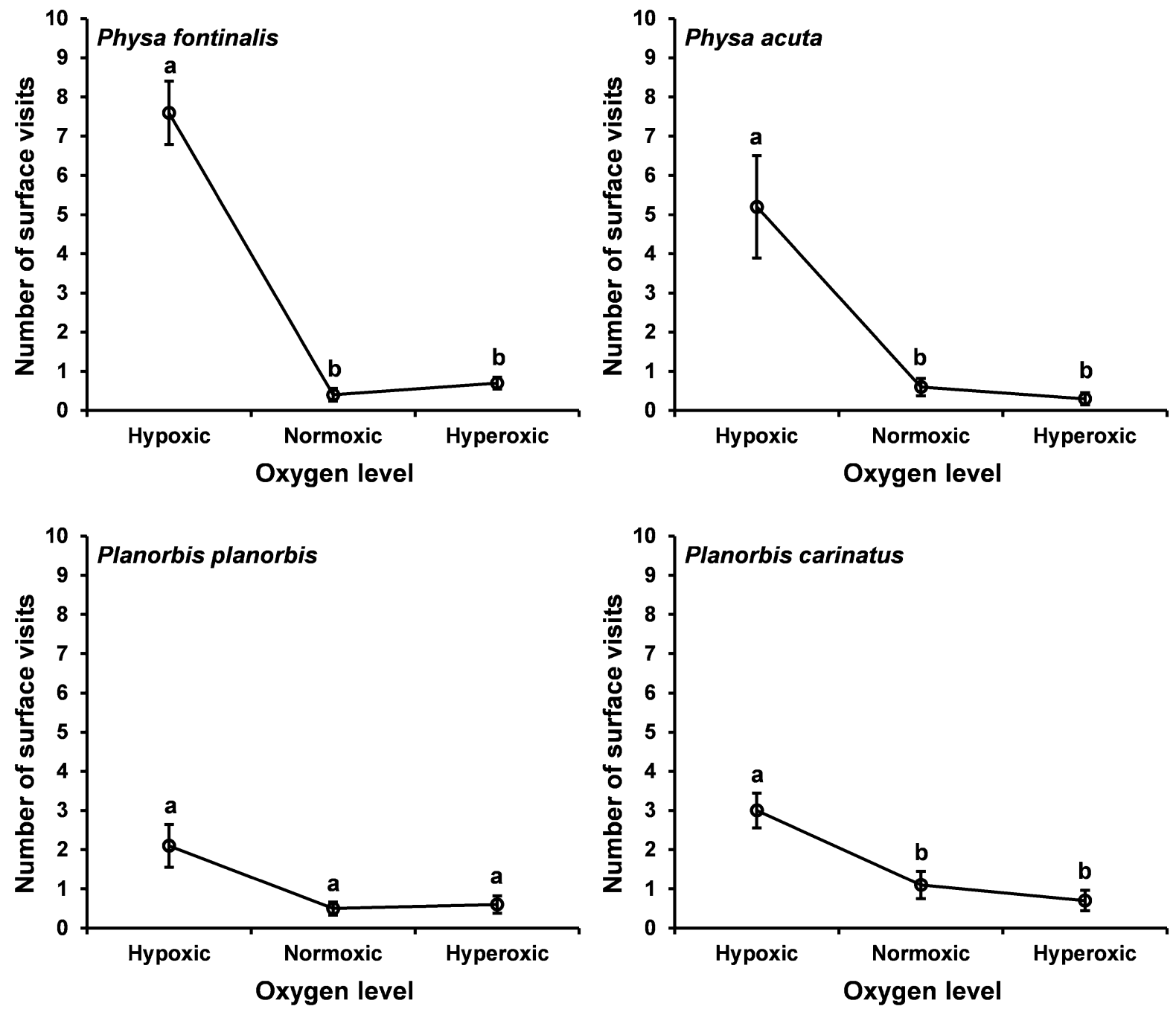

Fig. 2 The number of surface visits during the experiments under hypoxia, normoxia and hyperoxia for the six species. Letters indicate significant differences according to non-parametric testing (Mann-Whitney $U$ ), error bars represent standard error

Table 3 The results of the overall analysis of number of surface visits in relation to species, mode of respiration and oxygen level

\begin{tabular}{lccrr}
\hline Sources & SS (type III) & d.f. & $F$-ratio & $P$-value \\
\hline Species (mode of respiration) & 15.533 & 2 & 2.788 & 0.066 \\
Mode of respiration & 38.533 & 1 & 4.961 & 0.156 \\
Oxygen level & 397.95 & 2 & 71.435 & $<\mathbf{0 . 0 0 1}$ \\
Mode of respiration * oxygen level & 110.817 & 2 & 19.892 & $<\mathbf{0 . 0 0 1}$ \\
\hline
\end{tabular}

Significant results are indicated in bold

SS (type III) the sum of squares type III, d.f. degrees of freedom

lower capacity to regulate oxygen uptake in the Physidae. It is likely that due to the lower oxygen affinity of their haemocyanin and their larger reliance on aquatic gas exchange through their accessory gill, oxygen more readily becomes limiting under hot, hypoxic conditions, necessitating sharp increases in number of surface visits to meet oxygen demand. Similarly, differences in capacity for regulating oxygen consumption may also relate to the contrasting results found for the two planorbid species. In contrast 
to $P$. carinatus, $P$. planorbis did not show reduced heat tolerance under hypoxia nor did it increase its number of surface visits under hypoxia. While this could be attributed to a lack of statistical power caused by a greater variance in the data for $P$. planorbis, the species has also been reported to be less sensitive to poor oxygen conditions (e.g. Gittenberger et al., 2004). Indeed, a comparative study has shown that in $P$. planorbis haemoglobin levels are two-four times higher than those of $P$. corneus (Alaykrinkskaya, 1998). This would confer $P$. planorbis with improved ability to extract oxygen from the environment, providing it with increased capacity to regulate oxygen consumption.

While oxygen may become limiting under hypoxia, hyperoxia did not improve the thermal tolerance of any of the pulmonate gastropod species. Although the Physidae do show a slight increase in $\mathrm{CT}_{\max }$, this increase is not significant. The lack of improved heat tolerance under hyperoxia suggests that in pulmonate snails heat tolerance may not be limited by oxygen under normoxic conditions. Possibly, the increased oxygen uptake by increasing number of surface visits may already suffice to meet the higher oxygen requirements associated with the warmer conditions. Another possibility is that the capacity to deliver oxygen to tissues is not constrained by oxygen uptake but by oxygen transport. Blood oxygen transport may already reach a maximum under normoxia (e.g. when respiratory pigments are fully oxygen saturated), precluding the pulmonates to benefit from the hyperoxic conditions. If not set by oxygen, thermal limits can arise due to loss of other processes, such as loss of protein function due to denaturation; loss of membrane stability and neuronal dysfunction (Somero, 1995; Feder \& Hofmann, 1999; Pörtner, 2001; Klok et al., 2004; Verberk et al., 2013). Alternatively, if the CTs for these other processes are only slightly higher than the temperature at which oxygen becomes limiting, then hyperoxia will only have minor effects, alleviating constraints on oxygen delivery but with the next process in line breaking down at a temperature very close to the $\mathrm{CT}_{\max }$ observed at normoxia.

For the two caenogastropod species, we could not determine loss of movement as they retracted into their shell and closed their operculum in an attempt to isolate themselves from the surrounding stressful conditions, such as high temperatures (Winterbourn, 1969; Rao \& Devi, 1984; Hahn, 2005). Since both species retracted into their shell, this was used as their endpoint, as no further visual observations of loss of movement could be made. The temperature at which $B$. tentaculata and $P$. antipodarum retracted into their shell occurred at 28.9 and $28.6^{\circ} \mathrm{C}$, respectively. These temperatures were much lower than those at which loss of movement was observed in the pulmonates. The results for $P$. antipodarum would seem to be in accordance with its native distribution in New Zealand were it is not found in waters where the water temperature rises above $28.0^{\circ} \mathrm{C}$. Nevertheless, experimental studies have found the species to survive at water temperatures ranging from 32.4 to $34.0^{\circ} \mathrm{C}$ (Winterbourn, 1969; Quinn et al., 1994) and in its non-native distribution in Japan $P$. antipodarum was found in water ranging from 31.4 to $33.3^{\circ} \mathrm{C}$ (Hamada et al., 2013). While these studies employed different methodologies and are therefore not strictly comparable (Peck et al., 2009; Nguyen et al., 2011), they make it likely that the CTs found in this study for $P$. antipodarum were in fact not lethal. This is also corroborated by the response of the caenogastropod B. tentaculata which did emerge after the initial retraction into its shell. So, based on the endpoint first retraction into the shell it cannot be concluded whether or not oxygen plays a role in setting the lethal limit of caenogastropods. Interestingly, hyperoxia was found to increase the temperature at which $B$. tentaculata would retract into its shell for the last time $\left(\mathrm{CT}_{\text {last-retraction }}\right.$; Fig. 1$)$. This suggests that under normoxia, oxygen eventually could become limiting in caenogastropods at thermal extremes and that hyperoxia can alleviate this oxygen limitation. Also in a marine caenogastropod Nucella lapillus (Linnaeus, 1758), the thermal tolerance was found to decrease and increase under hypoxia and hyperoxia, respectively (Davenport \& Davenport, 2007; Gardeström et al., 2007). In contrast, thermal tolerance was unaffected by oxygen in Littorina littorea (Linnaeus, 1758). This species has a higher capacity to regulate oxygen uptake than $N$. lapillus due to a more efficient haemolymph circulation (Andrews \& Taylor, 1988; Davenport \& Davenport, 2007). Furthermore the gillarches of $L$. littorea are rigid and do not stick together when exposed to air (Jordan, 1939), giving this species some capacity to perform aerial gas exchange, conferring a greater capacity to regulate oxygen uptake. In addition, Winterbourn (1969) showed that the decline in activity of $P$. antipodarum under increasing temperatures was less rapid in super-oxygenated water. 
Thus, evidence for oxygen limited heat tolerance seems to be stronger in gill-breathing caenogastropods, possibly related to the lower capacity to regulate oxygen uptake of the gill-breathing caenogastropods compared to the lung-breathing pulmonates.

The results of this study show that hypoxia lowered the heat tolerance of three pulmonate species $(P$. fontinalis, $P$. acuta, $P$. carinatus) by $1.2-2.1^{\circ} \mathrm{C}$, whereas the heat tolerance of $P$. planorbis remained unaffected by oxygen. Differences among the pulmonate species in how their heat tolerance was affected by hypoxia could be related to differences in their capacity to regulate oxygen uptake, resulting from pulmonary air breathing versus gill breathing and using haemoglobin or haemocyanin as respiratory pigment. For one caenogastropod species, B. tentaculata, our results suggested hyperoxia may increase heat tolerance, and this could be related to its lower capacity to regulate oxygen, owing to its fully aquatic gas exchange mechanism (gill and skin underwater breathing). Finally, hyperoxia did not increase the heat tolerance of any of the pulmonate gastropods. Thus, heat tolerance limits of these pulmonate gastropods may not be oxygen limited under normoxia, possibly because of their high capacity to regulate oxygen consumption. Instead, in pulmonates other processes may become limiting at thermal extremes such as loss of protein function due to denaturation; loss of membrane stability and neuronal dysfunction.

Acknowledgments We thank Marij Orbons for supplying us with various materials needed for the experiments. We would also like to thank Nico Koopman and Willem Michiels for constructing the brackets that held the counter-current heat exchanger. Finally, we also thank three anonymous reviewers for their suggestions to improve our manuscript.

Open Access This article is distributed under the terms of the Creative Commons Attribution 4.0 International License (http:// creativecommons.org/licenses/by/4.0/), which permits unrestricted use, distribution, and reproduction in any medium, provided you give appropriate credit to the original author(s) and the source, provide a link to the Creative Commons license, and indicate if changes were made.

\section{References}

Alaykrinkskaya, I. D., 1998. Functional role of hemoglobin in the hemolymph of some representatives of the family
Planorbidae (Gastropoda, Pulmonata). Hydrobiological Journal 34: 84-88.

Andrews, E. B. \& P. M. Taylor, 1988. Fine structure, mechanism of heart function and haemodynamics in the prosobranch gastropod mollusc Littorina littorea (L.). Journal of Comparative Physiology B 158: 247-262.

Bennet, A. F., 1978. Activity metabolism of the lower vertebrates. Annual Review of Physiology 40: 447-469.

Calosi, P., D. T. Bilton, J. I. Spicer, S. C. Votier \& A. Atfield, 2010. What determines a species' geographical range? Thermal biology and latitudinal range size relationships in European diving beetles (Coleoptera: Dytiscidae). Journal of Animal Ecology 79: 194-204.

Chown, S. L., 2012. Trait-based approaches to conservation physiology: forecasting environmental change risks from the bottom up. Philosophical Transactions of the Royal Society B: Biological Sciences 367: 1615-1627.

Davenport, J. \& J. L. Davenport, 2007. Interaction of thermal tolerance and oxygen availability in the eurythermal gastropods Littorina littorea and Nucella lapillus. Marine Ecology Progress Series 332: 167-170.

Dejours, P., 1981. Principles of Comparative Respiratory Physiology. Elsevier, Amsterdam.

Ern, R., D. T. T. Huong, N. T. Phuong, T. Wang \& M. Bayley, 2014. Oxygen delivery does not limit thermal tolerance in a tropical eurythermal crustacean. Journal of Experimental Biology 217: 809-814.

Ern, R., D. T. T. Huong, N. T. Phuong, P. T. Madsen, T. Wang \& M. Bayley, 2015. Some like it hot: thermal tolerance and oxygen supply capacity in two eurythermal crustaceans. Scientific Reports 5: 10743.

Feder, M. E. \& G. E. Hofmann, 1999. Heat-shock proteins, molecular chaperones, and the stress response: evolutionary and ecological physiology. Annual Review of Physiology 61: 243-282.

Gardeström, J., T. Elfwing, M. Löf, M. Tedengren, J. L. Davenport \& J. Davenport, 2007. The effect of thermal stress on protein composition in dogwhelks (Nucella lapillus) under normoxic and hyperoxic conditions. Comparative Biochemistry and Physiology Part A: Physiology 148: 869-875.

Ghiretti, F. \& A. Ghirefli-Maguldi, 1972. Respiratory proteins in Mollusks. Mollusca 7: 201-217.

Gittenberger, E., A. W. Janssen, W. J. Kuijper, J. G. J. Kuiper, T. Meijer, G. van der Velde \& J. N. de Vries, 2004. De Nederlandse zoetwatermollusken: Recente en fossiele weekdieren uit zoet en brak water. Nederlandse Fauna 2. Nationaal Natuurhistorisch Museum Naturalis, KNNV Uitgeverij and European Invertebrate Survey-Nederland, Leiden.

Hahn, T., 2005. Respiration rates in Bithynia tentaculata (L.) (Gastropoda: Bithyniidae) in response to acclimation temperature and acute temperature change. Journal of Molluscan Studies 71: 127-131.

Hamada, K., N. Takeda, Y. Tatara, D. Ogata, M. Nakajima, T. Sonohara \& M. Urabe, 2013. Habitat description of Potamopyrgus antipodarum (Caenogastropoda: Hydrobiidae) in some areas of Japan: how far will it spread? Venus 71: 61-79.

Hutchinson, G. Y., 1993. The Zoobenthos. A Treatise on Limnology, Vol. IV. Wiley, New York. 
Jones, J. D., 1961. Aspects of respiration in Planorbis corneus L. and Lymnaea stagnalis L. (Gastropoda: Pulmonata). Comparative Biochemistry and Physiology 4: 1-29.

Jones, J. D., 1972. Comparative Physiology of Respiration. Edward Arnold, London.

Jordan, H. J., 1939. Het leven der dieren in het water. Oosthoek, Utrecht.

Jordan, H. J., 1951. Het leven der dieren in het water, 2nd ed. A. Oosthoek's Uitgevers mij, Utrecht.

Klok, C. J., B. J. Sinclair \& S. L. Chown, 2004. Upper thermal tolerance and oxygen limitation in terrestrial arthropods. Journal of Experimental Biology 207: 2361-2370.

Lefevre, S., I. Findorf, M. Bayley, D. T. T. Huong \& T. Wang, 2015. Increased temperature tolerance of the air-breathing Asian swamp eel Monopterus albus after high temperature acclimation is not explained by improved cardiorespiratory performance. Journal of Fish Biology (in press).

Lukowiak, K., E. Ringseis, G. Spencor, W. Wildering \& N. Syed, 1996. Operant conditioning of aerial respiratory behaviour in Lymnaea stagnalis. The Journal of Experimental Biology 199: 683-691.

Lutterschmidt, W. I. \& V. H. Hutchinson, 1997. The critical thermal maximum: history and critique. Canadian Journal of Zoology 75: 1561-1574.

Mark, F. C., C. Bock \& H. O. Pörtner, 2002. Oxygen-limited thermal tolerance in Antarctic fish investigated by MRI and ${ }^{31}$ P-MRS. American Journal of Physiology: Regulatory, Integrative and Comparative Physiology 283: R1254-R1262.

McMahon, R. F., 1983. Physiological ecology of freshwater pulmonates. In Russell-Hunter, W. D. (ed.), The Mollusca, Vol. 6., Ecology Academic, New York: 359-430.

McMahon, R. F. \& W. D. Russell-Hunter, 1981. The effects of physical variables and acclimation on survival and oxygen consumption in the high littoral salt-marsh snail, Melampus bidentatus Say. Biological Bulletin 161: 246-269.

Neven, L. G., N. Lehrman \& L. D. Hansen, 2014. Effects of temperatures and modified atmospheres on diapausing 5 th instar codling moth metabolism. Journal of Thermal Biology 42: 9-14.

Nguyen, K. D., S. A. Morley, C.-H. Lai, M. S. Clark, K. S. Tan, A. E. Bates \& L. S. Peck, 2011. Upper temperature limits of tropical ectotherms: global warming implications. PLoS ONE 6: e29340.

Peck, L. S., M. S. Clark, S. A. Morley, A. Massey \& H. Rossetti, 2009. Animal temperature limits and ecological relevance: effects of size, activity and rates of change. Functional Ecology 23: 248-256.

Pörtner, H. O., 2001. Climate change and temperature dependent biogeography: oxygen limitation of thermal tolerance in animals. Naturwissenschaften 88: 137-146.

Pörtner, H. O., 2002. Climate variations and the physiological basis of temperature dependent biogeography: systemic to molecular hierarchy of thermal tolerance in animals. Comparative Biochemistry and Physiology, Part A: Physiology 132: 739-761.

Pörtner, H. O., 2010. Oxygen- and capacity-limitation of thermal tolerance: a matrix for integrating climate-related stressor effects in marine ecosystems. Journal of Experimental Biology 213: 881-893.

Pörtner, H. O., L. S. Peck \& T. Hirse, 2006. Hyperoxia alleviates thermal stress in the Antarctic bivalve, Laternula elliptica: evidence for oxygen limited thermal tolerance. Polar Biology 29: 688-693.

Quinn, J. M., G. L. Steele, C. W. Hickey \& M. L. Vickers, 1994. Upper thermal tolerances of twelve New Zealand stream invertebrate species. New Zealand Journal of Marine and Freshwater Research 28: 391-397.

Rao, D. G. V. P. \& V. U. Devi, 1984. Effect of hypoxia on the oxygen consumption of an intertidal gastropod Morula granulata (Duclos). Monitore Zoologico Italiano 18: 24-32.

Rezende, E. L., L. E. Castañeda \& M. Santos, 2014. Tolerance landscapes in thermal ecology. Functional Ecology 28: 799-809.

Root, T. L., J. T. Price, K. R. Hall, S. H. Schneider, C. Rosenzweig \& J. A. Pounds, 2003. Fingerprints of global warming on wild animals and plants. Nature 421: 57-60.

Smith, S., M. H. Chen, R. G. Bailey \& W. P. Williams, 1996. Concentration and distribution of copper and cadmium in water, sediments, detritus, plants and animals in a hardwater lowland river. Hydrobiologia 341: 71-80.

Somero, G. N., 1995. Proteins and temperature. Annual Review of Physiology 57: 43-68.

Stevens, M. M., S. Jackson, S. A. Bester, J. S. Terblanche \& S. L. Chown, 2010. Oxygen limitation and thermal tolerance in two terrestrial arthropod species. Journal of Experimental Biology 213: 2209-2218.

Sunday, J. M., A. E. Bates \& N. K. Dulvy, 2011. Global analysis of thermal tolerance and latitude in ectotherms. Proceedings of the Royal Society B: Biological Sciences 278: 1823-1830.

Terblanche, J. S., J. A. Deere, S. Clusella-Trullas, C. Janion \& S. L. Chown, 2007. Critical thermal limits depend on methodological context. Proceedings of the Royal Society B: Biological Sciences 274: 2935-2942.

Verberk, W. C. E. P. \& D. Atkinson, 2013. Why polar gigantism and Palaeozoic gigantism are not equivalent: effects of oxygen and temperature on the body size of ectotherms. Functional Ecology 27: 1275-1285.

Verberk, W. C. E. P. \& D. T. Bilton, 2011. Can oxygen set thermal limits in an insect and drive gigantism? PLoS One 6: e22610.

Verberk, W. C. E. P. \& D. T. Bilton, 2013. Respiratory control in aquatic insects dictates their vulnerability to global warming. Biology Letters 9: 20131473.

Verberk, W. C. E. P. \& D. T. Bilton, 2015. Oxygen limited thermal tolerance is seen in a plastron breathing insect, and can be induced in a bimodal gas exchanger. The Journal of Experimental Biology 218: 2083-2088.

Verberk, W. C. E. P. \& P. Calosi, 2012. Oxygen limits heat tolerance and drives heat hardening in the aquatic nymphs of the gill breathing damselfly Calopteryx virgo (Linnaeus, 1758). Journal of Thermal Biology 37: 224-229.

Verberk, W. C. E. P., D. T. Bilton, P. Calosi \& J. I. Spicer, 2011. Oxygen supply in aquatic ectotherms: partial pressure and solubility together explain biodiversity and size patterns. Ecology 98: 1565-1572.

Verberk, W. C. E. P., U. Sommer, R. L. Davidson \& M. R. Viant, 2013. Anaerobic metabolism at thermal extremes: a metabolomic test of the oxygen limitation hypothesis in an aquatic insect. Integrative and Comparative Biology 53: 609-619. 
Wesenberg-Lund, C., 1939. Biologie der Süsswassertiere. Wirbellose Tiere. Verlag von Julius Springer, Wien.

Winterbourn, M. J., 1969. Water temperature as a factor limiting the distribution of Potamopyrgus antipodum (Gastropoda-Prosobranchia) in the New Zealand thermal region. New Zealand Journal of Marine and Freshwater Research 3: 453-458.

Winterstein, H., 1905. Wärmelähmung und Narkose. Zeitschrift für Allgemeine Physiologie 5: 323-350.
Woods, H. A., 1999. Egg-mass size and cell size: effects of temperature on oxygen distribution. Integrative and Comparative Biology 39: 244-252.

Zukowski, S. \& K. F. Walker, 2009. Freshwater snails in competition: alien Physa acuta (Physidae) and native Glyptophysa gibbosa (Planorbidae) in the River Murray, South Australia. Marine and Freshwater Research 60: 999-1005. 